\title{
On the Motivations of a Skeptic, and Her Practice
}

\section{BRYAN MADDOX / Oxford OH/}

A skeptikos in the tradition of Pyrrho and Sextus Empiricus is first and foremost not a doubter or a disbeliever but a restless 'seeker'. To be truly 'skeptical' in the Pyrrhonian sense is not simply to suspend judgement on any particular issue or range of issues, but to aim for a certain untroubled state of mind and to confront troubling issues accordingly. Like medicine, Skepticism is presented as a normative practice, though a peculiar one in that it pursues an ideal state without affirming any doctrinal ideas about this state or how to achieve it. Instead, the Skeptical teachers merely offer suggestions, outlining a flexible and pragmatic method for dispelling belief without dogmatically affirming absolute disbelief. Yet there remains a tension between the aim of Skepticism and the method: for while the Pyrrhonian tradition of Skepticism is outspoken about its aim and its therapeutic value, in practice its own critical method ultimately eclipses its object and undermines the Skeptic's evaluative abilities. This does not at all foreclose or negate the therapeutic effects of the method, but it does displace them from the position of ultimate aim, value, or motivation and unbind the ideal state they purportedly approach from any fixed definition. In the following article I will analyze a few key passages from the most developed and rigorous account of Pyrrhonian Skepticism, the one offered by Sextus Empiricus in his Outlines of Skepticism $\left(\sim 2^{\text {nd }}-3^{\text {rd }}\right.$ century CE), and engage with other articles on the aims of the Skeptic by Jonathan Barnes (1997) and Pascal Massie (2013) in order to 
show how the stated goals of Skepticism are able to withstand critical scrutiny on the terms of its own method, but not without ultimately being subsumed in an unbounded and unbinding process by which the Pyrrhonian method opens itself up to potentially unlimited possibilities.

Sextus presents the Outlines as a manual of techniques for fending off beliefs and cultivating a supremely unbelieving state of mind, in the hopes of achieving an enigmatic psychic state he calls ataraxia: literally, lack of tarache, or mental disturbances. Sextus firmly opposes himself to philosophers who hold to dogmas about the nature of truth and reality, and in the Outlines he critiques many of the various propositions and arguments that constitute "what they call philosophy", namely the systematic, dogmatic study of "logic, physics, and ethics" (Sextus PH II 12-13). Where these "Dogmatists" (Sextus's pejorative term for all non-Skeptical philosophers) have sought a state of tranquility similar to ataraxia by ascertaining profound truths, Sextus, having found that the quest for truth bore him no fruit, found instead that by juxtaposing contrary and equally persuasive arguments to each other, the resulting equipoise would engender in him a feeling of equanimity. So while the Skeptic is steeped in the philosophical traditions of her time and place and participates in philosophical conversations, she is a seeker after tranquility and equanimity, to which wisdom and truth are incidental. But is her tranquility limited to matters of intellectual puzzlement, or would the Skeptic be able to meet with equanimity those more complex emotional manifestations of her deep-seated beliefs? Conversely, if she were to concede a much broader scope to Skepticism and suppose it might have additional positive, even life-altering consequences, how can she do this without positing her own theory about the dynamics of beliefs, emotions, and the mind?' And once she has attained a measure of peace, will she continue to search further or rest on her laurels?

In the following exploration of the motives ${ }^{2}$ that undergird and maintain the Skeptical habits of thinking outlined by Sextus, I will attempt to respond to these questions and draw out some of the therapeutic possibilities and problems of this unorthodox approach

1 Talking about Sextus' treatment of belief and tarache without resorting to an implicit theory of mind is especially tricky. Everson (1991) is rightfully wary of unstated assumptions that might condition how Sextus talks about appearances, and we may include among these the appearance and disappearance of tarache in conjunction with the conscious contemplation of a belief. In what follows I have been careful to frame what I say about the mental states of the Skeptic in terms of appearance and speculation, without developing such a theory. I have instead tried to expose specific dogmatic assumptions made by Barnes and Sextus, at times by juxtaposing them to possible alternative psychological dogmas, not in order to advance these alternatives but rather to open up the field of possibility where belief and tarache are concerned.

${ }^{2}$ By this I mean simply the Skeptic's personal reasons for 1.) initially adopting the Skeptical method, and 2.) persisting in the use of this method, and developing it into a full-blown lifestyle. Sedley (1983) distinguishes these two moments and suggests that there was a necessary disjunction between the motives of the historical progenitors of Skeptical disciplines and those of their more rigorously anti-doxastic followers. While later in this paper I sketch out the possibility of a similar disjunction between the ways the Skeptic might act on her own motives, I aim to demonstrate that there can be more continuity between the adoption and subsequent development of Skepticism than Sedley admits. There is no reason not to suppose that one person could successively undergo a "founding" stage, and an "advanced" stage in which she questions some of the presumptions of the founding stage without abandoning her original motives. For more on this, see my conclusion. 
to inquiry. A great deal of confusion owes to assumptions in Sextus's text that remain unstated and conflated in the related concepts of ataraxia and tarache, assumptions that I will explicate in order to make two important points. First, there are at least plausible connections to be made between contradictions internal to one's set of beliefs and mental disturbances that, though prompted by life events, might be rooted in those contradictions in ways that are "unclear by nature". From this it will follow that since the Skeptic's practice deals generally with beliefs, she may hope, though not expect, that it could yield relief from more than overt puzzlement. And second, since ataraxia conceived as an ultimate state of relief from all tarache is not sufficient to set Skeptical practice apart from other pursuits which promise the same thing such as Dogmatic philosophy or religious practices, overt relief from puzzlement remains the most reliable distinguishing mark of successful Skeptical practice. In establishing the first point I will be correcting some mistaken conclusions about the therapeutic potential of Pyrrhonian Skepticism drawn by Jonathan Barnes (1997) that would drastically limit the scope of Skeptical inquiry and that I take to be characteristic of some sympathetic contemporary readings of Sextus. According to Barnes, the least inquisitive mind makes for the happiest Skeptic, which I find doubtful in light of passages from the beginning of the Outlines about the tarache caused by beliefs in contexts far removed from theoretical inquiry (Sextus PH I 27). Though their implications are understated in the rest of Sextus's work, the presence of these passages that hint at a link between belief and the many forms of tarache encountered in practical life indicates that the benign appeal of reformulations of Skepticism like Barnes's belies the profound and disturbing possibilities latent in Sextus's anti-doxastic critical method.

However, these possibilities will vanish if they are mistaken for promises and are pursued programmatically according to some new pseudo-Skeptical dogma. So I will qualify my excursus on these passages with the caveat that the Skeptic must carefully distinguish between what merely appears possible and what appears probable based on past experience, and that she cannot judge the merits of Skepticism against other inquisitive lifestyles on the basis of possibilities alone. Thus my second main point will respond to Pascal Massie's concerns (2013) about an unbridgeable gap between Skeptical practice and its goal, ataraxia, by both relating and clearly distinguishing what I will refer to as the determinate and indeterminate senses of "relief from tarache". To do this, I will bring Sextus's discussion of recollective signs and inferential signs to bear upon my analysis of Skeptical motivation. Put briefly, recalling associations is possible without holding beliefs, while making inferences is not. I will show that from this distinction it follows that the pursuit of immediate relief from intellectual tarache is consonant with the Skeptical preference for recollection over inference. Conversely, the notion of a more radical transformation of the perennial experience of deep-seated disturbances goes beyond recollection into the realm of unreliable speculation. This is not to say that the latter motivation does not play a role, but only that it gives the Skeptic no reason to believe that her kind of inquiry will make her a profoundly happier person than any Dogmatist, which would amount to a pseudo-Skeptical dogma of ataraxia. However, she needs no such reason to entertain the possibility. On the contrary, it would be dogmatic to assert that any form of 
tarache that lacks an immediate perceptible connection to beliefs must therefore not have anything to do with beliefs, or that such unclear tarache must categorically be impossible to quell through the gradual divestment of beliefs.

Finally, I will take up Massie's suggestion that for Sextus, "the inquisitive activity of the desiring intellect is itself valuable" and that the Skeptic, unlike other philosophers, seeks to prolong inquiry indefinitely (Massie 2013: 230). While I will show that Skeptical inquiry is perfectly justified and useful as a therapeutic practice, I agree with Massie that a characterization of skeptesthai as a purely negative means to an end is not quite satisfying, and it has too much in common with the attitudes of Sextus's Dogmatic opponents. How could the occasional use of Skeptical techniques to produce equipoise evolve instead into a 'lifestyle', such that we could make a meaningful distinction between those who take the Skeptic's 'medicine' now and then from those who identify themselves as vocational Skeptics? In the final section of this paper, I will show how the consistent use of Skeptical techniques might inculcate a Skeptical disposition that is motivated by more than the hope for relief from determinate or indeterminate conceptions of tarache. Rather than speculate about the content of this motivation, I will trace its possible genesis in the indeterminacy of the relation between belief and tarache and the consequent open-endedness of the possible benefits of habitual Skeptical practice. Once the Skeptic has reached a point in the ongoing nullification of all her accumulated beliefs where she is able to question the supposed limitations of the scope of Skeptical inquiry - including even those limitations seemingly posited by Sextus himself - the end-directedness of the activity begins to fall by the wayside. As it is increasingly underdetermined by the multifarious and obscure appearances of tarache, ataraxia is no longer adequate to explain the perpetuation of inquiry, which becomes habitual and endless. Deferring the question whether and in what respect "the inquisitive activity of the desiring intellect" might be valuable, I will conclude instead that it appears to be invaluable, inestimable in its value and scope, and that is what makes it a lifelong pursuit with no end in sight.

\section{Ends Clear and Unclear}

What is the stated aim of the Skeptical lifestyle? Sextus says at the outset that it is "tranquility [ataraxia] in matters of opinion and moderation of feeling in matters forced upon us" (Sextus PH I 25). Ataraxia is "freedom from disturbance [tarache]" (Sextus PH I 10). And what is the source of this tarache? Sextus gives two different accounts: on the one hand, it is caused by "the anomaly in things" that puzzles those who have investigated them (Sextus PH I 12). On the other hand, it is caused by "the opinion that things are good or bad by nature"; whether they lack these good things or acquire them, those who pursue them fear persecution and privation (Sextus $\mathrm{PH}$ I 27). Those who act on their beliefs are troubled because those beliefs engender expectations which magnify grief and worry, whether they are thwarted or fulfilled; those who investigate their beliefs are 
troubled by the appearance of an anomaly. Neither awareness of their beliefs nor ignorance of them can prevent the turmoil those beliefs bring about.

Sextus sees the Dogmatic philosophers as his primary intellectual opponents, because the Skeptic is for him an ex-Dogmatist, an apostate. "Men of talent", he states (and he specifies that he has Skeptics in mind when he reiterates this point at I 26), "troubled by the anomaly in things and puzzled as to which of them they should rather assent to, came to investigate what in things is true and what is false, thinking that by deciding these issues they would become tranquil" (Sextus PH I 12). This is his account of the origin of philosophical inquiry. Where the Dogmatist continues to believe that tranquility can only be attained by those who learn the truth and resolve the anomaly, the Skeptic entertains doubts about both the accessibility of truth and the connection of truth to tranquility. What they have in common is that they are both well aware of the anomaly in things.

Thus, many of Sextus' arguments are not directed at those who suffer in ignorance of anomalies, and he does not investigate the consequences of unreflectively holding and acting on a belief. While reading his Outlines of Pyrrhonism, it is easy to overlook the possibility that an unexamined belief can do much harm, and it is easy to conclude that those afflicted with the inclination to investigate their beliefs, namely the "men of talent" or philosophers, suffer more from tarache and are more in need of Skeptical remedy than those who act and live unreflectively. Jonathan Barnes succumbs to this mistake when he supposes that since one "will only suffer from [tarache] if [one] perceives a worrying [anomaly] in things", then "a man who suffers only mildly from [tarache]" - that is, one who perceives few anomalies in his beliefs - "may be a perfect Pyrrhonist; for he may achieve complete [ataraxia] by exercising his [suspension of judgement] and reaching [epoche-equipoise] in a very modest way” (Barnes 1997: 90; bracketed words originally printed in Greek alphabet). "Others," he says, and here we may imagine he means those very 'men' who think their affliction is a 'talent', "who find the whole of life a sea of troubles, will not be set at rest until they have achieved universal [epoche]" (Barnes 1997: 90). In what follows I will show how this conclusion, based on an overtly therapeutic interpretation of Sextus, is unwarranted in ruling out possible connections between belief and myriad manifestations of tarache. Perhaps in the interests of 'taming' Skepticism and making it seem more compatible with ordinary life, Barnes prematurely confines the Skeptical method to the realms of contemplation and speculation, cutting it off from those beliefs which inform our judgements and actions.

It is because of his belief that tarache can only be caused by the perception of an anomaly, and not by an unperceived incongruity between beliefs, that Barnes establishes his continuum of "Rustic" and "Urbane" Skeptical treatment (Barnes 1997: 91). After he defines these as two distinct stances toward the status of certain categories of beliefs, Barnes concludes that all Skeptics oppose arguments to each other only to produce epoche concerning those issues that give them tarache (Barnes 1997: 90). The Urbane Skeptic, like the "Country Gentleman" coined by Myles Burnyeat (from whom Barnes draws the "Rustic-Urbane" distinction), is insulated from much of the puzzlement that plagues philosophers, for she simply does not feel bothered by certain beliefs and feels 
no reason to question them. ${ }^{3}$ By contrast, the Rustic Skeptic is one who worries over the epistemic foundations of seemingly everything (Barnes 1997: 61-62). I call Barnes's distinction not a binary but a continuum because the question of whether to subject any particular belief to Skeptical inquiry is determined by whether the particular believer feels any tarache about the belief. Because any collection of beliefs commonplace and abstruse can be accompanied by an arbitrary distribution of tarache, the Rustic Skeptic and Urbane Skeptic should be conceived of as two ideal types indicating natural states of relative anxiety or indifference. The Urbane Skeptic perceives few troublesome anomalies to begin with; the Rustic Skeptic perceives many.

If Barnes were right and an 'unperceived anomaly' - which I take to mean a potential conflict or contradiction between held beliefs that never becomes an object of conscious reflection ${ }^{4}$ - were a cause for no concern, then in the quest for ataraxia the person of "talent" would find herself at a great disadvantage to the ignoramus. Barnes is probably drawing this inference from the coda to the Outlines where Sextus states that one ought to use arguments of proportionate "strength" to the "conceits" that require suspension:

Just as doctors for bodily afflictions have remedies which differ in potency, and apply severe remedies to patients who are severely afflicted and milder remedies to those mildly afflicted, so Sceptics propound arguments which differ in strength - they employ weighty arguments, capable of vigorously rebutting the dogmatic affliction of conceit, against those who are distressed by a severe rashness, and they employ milder arguments against those who are afflicted by a conceit which is superficial and easily cured and which can be rebutted by a milder degree of plausibility. (Sextus $P H$ III 280-281)

Sextus's frequent usage of medical analogies like this has led several commentators to adopt decidedly therapeutic interpretations of his philosophy, of which I take Barnes's valorization of Urbane Skepticism to be emblematic. ${ }^{5}$ I will show later that the interpreta-

${ }^{3}$ Burnyeat's 'Gentleman' is instead insulated by a kind of professional disingenuousness, an ability to entertain "transcendental doubt" and "empirical confidence" regarding any belief, which he claims to derive from Kant (Burnyeat 1997). In practice, this means that Burnyeat’s Gentleman, like some professional philosophers, lives a life totally unaffected by his philosophical questions and doubts. Needless to say, this attitude towards philosophy has very little to do with Pyrrhonian Skepticism as understood by Sextus.

${ }^{4}$ I take this dubious formulation from a passing comment by Barnes that "Some men [sic] may never light upon the anomaly in the thing" (Barnes 1997: 90). Of course it is highly unclear whether an anomaly is the sort of thing that can literally be "in things" rather than in a perception, raising the old Sophistic question whether things are inherently unnamable and unintelligible - certainly not a notion the Skeptic would assent to, though perhaps one about which she would have to suspend judgement one way or the other.

5 Jessica Berry (2011) employs something much like Barnes's Urbane-privileging interpretation in her favorable comparison of Sextus and Nietzsche. Curiously, she believes that Barnes reads Sextus as either Rustic or disingenuous because according to him "the urbane skeptic lays claim to at least some beliefs of the ordinary, everyday variety". But Barnes also states at the end of his article "The Beliefs of a Pyrrhonist" that "Pyrrhonism may be Rustic or Urbane ... Everything depends on the particular state of the patient" and that he thinks Sextus "would" have answered in the same vein "had the question [concerning the scope of epoche] been put to him directly" (Barnes 1997: 91). While Berry says she explicitly rejects the claim that Sextus has "therapeutic" preten- 
tion of Skepticism as a therapeutic practice is not strictly wrong, but that that very practice ultimately undermines its own therapeutic criteria and evolves into a self-motivated lifestyle.

Notice, however, that here Sextus specifies that the arguments be proportionate to the conceits, not the doubts, of the patient. This already indicates that Barnes has the priority of belief and doubt switched around - that for Sextus it is not the one who perceives the most anomalies but the one who is most oblivious to anomalies because of his egregious conceits who is in need of the strongest medicine. This is because Sextus does not assent to the assertion that only those who reflect on their own beliefs (and question their own "conceits") are in for trouble. Instead, he states that tarache awaits those who pursue anything they believe to be good and fear anything they believe evil:

For those who hold the opinion that things are good or bad by nature are perpetually troubled. When they lack what they believe to be good, they take themselves to be persecuted by natural evils and they pursue what (so they think) is good. And when they have acquired these things, they experience more troubles; for they are elated beyond reason and measure, and in fear of change they do anything so as not to lose what they believe to be good (Sextus $\mathrm{PHI} 27$ ).

Later he adds that "ordinary people," when they experience immediate pain and privation $^{6}$, "are afflicted by two sets of circumstances: by the feelings themselves, and no less by believing that these circumstances are bad by nature" (Sextus PH I 30). To Sextus, the problem with dogmatic beliefs runs much deeper than the unseemly incongruities they present to consciousness. In the grip of belief, a person may be afflicted with anxieties and indignities that are entirely the product of not-fully-conscious expectations confounded by anomalies encountered during the pursuit of satisfaction in life. While it is not guaranteed that any given belief qua belief will be responsible for delusion and grief any more than it is guaranteed that a perceived anomaly will cause tarache, it is also true

sions, she does take Sextus to be, like Nietzsche, primarily concerned with cultivating "health" in a broad sense, and she, like Barnes, takes Rustic Skepticism to be symptomatically unhealthy or associated with dire health.

${ }^{6}$ We can now, in passing, distinguish between three sources of tarache: 1.) reflection upon anomalies; 2.) unclear frustrations possibly caused by holding problematic beliefs; and 3.) external stimuli that seem to irresistibly compel tarache in the form of bodily sensations like pain and hunger. We must even leave the door open for a fourth category of tarache, which would include any tarache attributable neither to beliefs, nor anomalies, nor biological stimuli: original sin, supernatural curses, existential nausea, or any number of other hypothetical causes are equally plausible explanations for the Skeptic. But all that matters to the Skeptic is the immediate sting of tarache, and the effectiveness or ineffectiveness of treatment. So I will confine my analysis to the first two categories on the hypothesis that if suspension of judgement did have an unclear positive effect on some tarache, then because suspension of judgement deals entirely with beliefs, we might infer that that tarache must also have had something to do with beliefs. Later in this paper we will have reason to question this etiological taxonomy of forms of tarache. 
that apparent harmony between appearances and the beliefs that one can call to mind should not be taken as a sure sign that any of one's beliefs are unproblematic.?

Sextus's brief treatment of unreflective tarache is confined to his analysis of "opinions that things are good or bad". But those value-neutral beliefs that are ancillary to the evaluations that motivate action, factual beliefs or beliefs about reasoning and inference, are also liable to lead the believer astray when they inevitably fail to account for the vagaries of the anomalous world in which she designs to realize her ambitions. Both the normative beliefs that give form to her hopes and the positive beliefs that raise her hopes are implicated in the dashing of those hopes against unforeseen obstacles. So it seems that if we cannot rule out on the basis of reflection alone the possibility that any belief, positive or normative, can imperil our tranquility, as Barnes hoped to do with his narrow conception of belief-related tarache, then the philosophical inquirer, for all her perplexity, has got a head start on her oblivious counterpart, for she is more fully aware of the extent to which the reliability of her belief system is compromised. Barnes's ideal types of Rustic and Urbane Skepticism can still be situated on the same continuum, but become less useful for prescribing epoche because they were conceived only with one sort of tarache in mind, namely that which presents itself in tandem with a perceived anomaly. Now the Rustic Skeptic, who before seemed to be hindered by her overwhelming inclination to doubt, emerges as a more sensitive, self-aware, and lucid inquirer, while the Urbane Skeptic struggles to let go of her more deeply held convictions.

\section{Determining and Un-determining Ends}

In the following three subsections I will consider an objection raised by Pascal Massie (2013) to the interpretation of Skepticism that I have described above as "Rustic": that to deliberately attempt to question all of one's beliefs and suspend all judgements including 'unconscious' judgements implies that one holds an unwarranted and therefore dogmatic belief that all beliefs cause tarache. Massie offers a solution to his own objection which saves the Skeptic from dogmatic self-contradiction without making her what we would call a Barnesian Urbane Skeptic and without, and this is his second objection, making her unworthy of the name skeptikos, perpetual searcher. I find Massie's solution intriguing but vague, and also unnecessary to answer his primary objection. After I demonstrate in

\footnotetext{
7 This is related to the problem of inference that I will address later. For how can a sign be taken to indicate anything of which one has never had a direct impression, unless one holds dogmatic beliefs connecting what is clear to what is unclear (cf. PH II 11)? And how can one have a clear and direct impression of the connection between a feeling of tarache in a frustrating situation and all the various subsidiary beliefs that have led one to adopt the frustrated expectation? For example, the nebulous feeling that one is 'entitled' to something may owe to the way one was raised to perceive the world and one's place in it. If upon reflection one cannot 'find in oneself' any association between entitlement and upbringing, one cannot in good faith conclude with certainty that one has done an exhaustive investigation of one's motives, whatever that would entail. So when determining the culpability of any given belief, even a less committed skeptic than Sextus ought to be skeptical of an attempt to interpret an absence of evidence as evidence of an absence.
} 
the second subsection that there is another, simpler way to solve the problem by reexamining what counts as a reliable inference for the Skeptic, I will show in the third subsection how a careful consideration of what the Skeptic does and does not infer about the success of her own method also leads to an unexpected solution to Massie's second objection, though one that raises even more questions about the overall aim of Skeptical practice.

\section{i. Massie and the Intrinsic Value of Inquiry: A Solution with Two Problems}

Our Rustic Skeptic attempts to resolve the turmoil caused by her beliefs by pursuing her investigation until every lead runs cold. She digs up deep-seated beliefs and examines them under a harsh light, turning over alternative explanations and opposing arguments in her mind until she no longer feels impelled to judge one way or another. Once she is able to suspend judgement on the matter completely, the anomaly will loosen its grip on her and she will find relief from tarache in her thoughts and in her actions. The apparent and unapparent effects of her dogmatic beliefs will be neutralized through their suspension.

There is a problem with this picture: it presupposes that the Skeptic believes that arguments will lead to suspension of judgement, and that suspension will put an end to all of her turmoil. In her quest for ataraxia, could the Skeptic be in the grip of another dogmatic delusion? Pascal Massie (2013) has highlighted the trouble with ascribing to Sextus the dogmatic belief that ataraxia will follow from Skeptical practice or inferring from this that ataraxia is really the primary motivation for Skeptical inquiry. While I completely agree with his criticism of the treatment of ataraxia as it is described by Sextus as an end and explanation for Skeptical practice, I find the alternative he briefly proposes to be intriguing yet underdeveloped. Massie argues that the Skeptic is unique among philosophers for her unequivocal commitment to keeping her investigation open, rather than seeking a truth that would put her search at an end. Her name literally means "one who inquires, one who is searching and looking out (skeptesthai)", and Sextus says that she, unlike the Dogmatists who believe they have hit upon the truth, is "still investigating", and that "the Skeptical persuasion is also called Investigative, from its activity in investigating and inquiring" (Massie 2013: 215; Sextus $\mathrm{PH}$ I 3, I 7). This, Massie goes on, implies that she does not seek ataraxia in the same way that the other philosophers are after truth. If ataraxia played an analogous role as the ultimate and overriding end of her inquiry, then she would be little different from the dogmatists chasing after their cataleptic fantasies, and no more deserving than they of the title of a true searcher, a skeptikos par excellence. Instead, Massie proposes that "the inquisitive activity of the desiring intellect is itself valuable" and that Sextus "commits philosophy to be infinite inquiry" (Massie 2013: 215). However, he does not elaborate on why the Skeptic would value inquiry as an end in itself or what good it would do aside from bringing her ataraxia and relief from tarache, and he cites no overt indication in Sextus's Outlines of Pyrrhonism that the Skeptic should derive some sort of fulfillment from inquiry for its own sake. 
It remains an interesting possibility and one that I will return to later; but the most obvious difficulty with Massie's proposition is that it is not at all attested to in ancient Greek formulations of skeptical practice, which promise no positive fulfillment or flourishing like arête or eudaimonia, only the negative state of ataraxia, freedom from worry. The specific character of the intrinsic value of inquiry is also cause for concern. While it is possible that Skeptical activity might produce a pleasure of its own, and even that this pleasure had an unseen hand in motivating Sextus and his fellow Pyrrhonians to pursue their odd project with passion and verve, to suppose that Skeptics might additionally value inquiry for the pleasure it produces is not strictly the same as saying that the inquiry is in itself valuable. We are not likely to find a positive explanation of what it means for something to be intrinsically valuable in Sextus's writings, let alone why inquiry might be intrinsically valuable. If there is some such implicit valuation at work, Sextus remains silent about it, leaving us in the meantime with two problems on the table. First, a thoroughgoing Skeptic apparently cannot believe that the abolition of beliefs will lead to anything good or bad if she also intends to follow through with that abolition; and second, it is unclear why we should call someone who seeks reprieve from tarache through the abolition of her beliefs a Skeptikos rather than, say, a "Self-Therapist". The first of these problems seems far graver, and I believe that it can be satisfactorily addressed without straying far from Sextus's explicitly stated aims. So setting aside the Skeptikos problem and Massie's suggestion for now, I would like to pursue another avenue: the Skeptic's raison d'être, or at least her most pressing reason for embarking on a course of equipoise, may have more to do with soothing the sting of tarache than achieving some more elusive state that only follows from Skeptical activity "fortuitously, as a shadow follows a body", if at all (Sextus PH I 29). In what follows I will apply Sextus's advice (for we obviously cannot call it a "theory") concerning reliance on recollective signs to determine what we can or cannot reasonably assume in advance about the efficacy of suspension of judgement for soothing various manifestations of tarache based upon past experience alone. The ways that tarache and relief from tarache present themselves to us tell us nothing about the nature of tarache, and it would be unwise to make assumptions, be they optimistic or pessimistic, about the limits of the Skeptical method for achieving ataraxia.

\section{ii. Recollective Signs of Relief}

We have considered two sources of tarache: conscious awareness of anomalies, and frustration and anxiety obscurely caused by problematic beliefs. The Skeptic presumably has an immediate impression of the first source of tarache - her discomfort accompanies her contemplation of the problem as irresistibly as pain follows an injury. Likewise, one would suppose that if she is able to suspend her judgement and disengage from the problem, she should immediately perceive her pain to disappear. If one can imagine a Skeptic drinking when thirsty or recoiling from a snarling dog (as in Diogenes's memorable anecdote about Pyrrho), if one permits the Rustic Skeptic to exhibit any purposive behavior at 
all, it seems one would have to take her word for it when she says that suspension of judgement eases her mind (cf. Sextus PH I 4, I 21-24, I 29, and Diogenes Laertius IX 66-67, cited in Long \& Sedley 1987).

If we only considered ataraxia in relation to this first kind of tarache, then we would already have grounds to contest Massie's claim that Sextus offers no way to connect Skeptical practice to ataraxia. Massie's criticism only takes ataraxia in the indeterminate sense, as a distant and mysterious end toward which the Skeptic's many arguments and exercises strive. But he concedes that the Skeptic is able to follow appearances while suspending her judgement about beliefs, so if tarache presents itself as an appearance, then the Skeptic is not forced to resort to any sophisticated causal reasoning to justify her therapeutic practice: she nurses the pain immediately engendered by her beliefs like a dog who licks her wounds for comfort. However, while Massie's objection does not apply to all forms of yearning for a-taraxia (literally absence of tarache), I think it would be a mistake to discount his insight when it should instead guide us to make a decisive distinction between determinate and indeterminate senses of ataraxia corresponding to the clear and unclear appearances of tarache, respectively.

For there is no reason to suppose that the other kind of tarache, namely the frustration of our ambitions and the dread of our fears due to beliefs related to "the opinion that things are good or bad by nature", will reveal in itself an immediate connection with its cause. According to Sextus' theory of signs (Book II, Chapters X-xiv), there is no recollective connection possible between the sign and what it signifies if the latter is unclear by nature; such a connection can only be inferred, and arguments for and against such an inference can always be opposed to produce equipoise. He borrows these distinctions between recollective and inferential signs and things unclear for the moment and things unclear by nature from the Dogmatists. Things unclear for the moment are things that can be perceived but that are not presently perceived, including all the things one has ever seen, heard or felt that one does not see, hear, or feel right now, while things unclear by nature cannot be perceived or have never been perceived, like the structure of an atom 8 (Sextus PH II 10.97-98). Things unclear for the moment can be apprehended by recalling previous perceptions, while the attributes and even the existence of things unclear by nature can only be inferred from beliefs; for an inference "signifies that of which it is a sign not by having been observed evidently together with the thing it signifies but from its proper nature and constitution" (Sextus PH II 10.101). Since this propriety of the sign to what it signifies can also be brought into question, the unclarity of the thing signified compounded by the unclarity of its relation to its sign will demand an infinite regress of purported indications of the validity of other indications (Sextus PH II 10.124). After enumerating these and many other (mutually contradictory, of course) reasons for

\footnotetext{
${ }^{8}$ I follow Sextus in setting aside discussion of "things unclear once and for all" (Sextus PH II 10.97) and I suspect that the distinction between them and things "unclear by nature" can only be supported by recourse to beliefs.
} 
and against the possibility of inference, Sextus finally finds himself persuaded only by those signs that require no argument from inference, namely, his recollections of previous temporal coincidences - e.g. the coincidence of smoke and fire, of treatment and recovery from an illness, of injury and pain (Sextus $P H$ II 10.102). ${ }^{9}$

It seems that the situation in Section I 27 of the Outlines (concerning "those who hold the opinion that things are good or bad by nature") poses this very problem: the persistent disturbance could signify one or many mistaken factual premises, a hidden factor unaccounted for, a small flaw in reasoning, or even a conflict internal to a person's system of values. But if an association or an immediate coincidence of impressions does not simply present itself to the Skeptic, she has nothing to work with. It is as if she were instead presented with an unsettling picture, and this picture were composed of many brushstrokes of many colors portraying many objects and contours. Any given brushstroke, perhaps all of them or just a few, might be responsible for producing the unsettling impression the picture has on the viewer, but the brushstrokes make no such impression taken by themselves; they may even be indiscernible. Likewise, the enormous variety of beliefs and values that comprise a desire or an expectation can be as numerous and as subtle as brushstrokes; where reflection presents successive portraits of individual beliefs, anticipation appears against a landscape of beliefs blended together. When that anticipation is thwarted for whatever reason, the resulting tarache is taken in as if at a glance, without clearly indicating one offending assertion or another.

Barnes treats tarache as if it can only be caused by patent incongruities between beliefs and perceptions. He cannot profess this outright, as it sounds exactly like what it is: a dogmatic belief about the nature of belief and tarache. Perhaps the example of the landscape composed of beliefs sketched above implies a theory of mind that is no less dogmatic, but I merely present it to counterbalance Barnes's narrow picture in true Pyrrhonian fashion, and to suggest that beliefs may produce tarache in ways that will forever remain obscure to the Skeptic. Like the myth of ataraxia as portrayed by Massie, the Skeptic can only wonder and doubt whether her tarache has anything to do with unwitting prejudices, obscure psychic phenomena, or other causes taken to be unclear by nature. Nevertheless, it is entirely plausible that ataraxia and relief from inexplicable tarache coincide in the form of an indeterminate end that exceeds the determinate ends of Skeptical practice, for both indeterminate and determinate ends manifest an overarching desire to be free of any and all kinds of tarache. I will show in the following subsection how the domain of indeterminate ends, or possible instances in which tarache might be

\footnotetext{
9 Not only my own argument concerning immediate relief from tarache, but also an awful lot of Sextus's arguments against the apraxia charge (the allegation that Skeptics are incapable of acting or living in the world) hinge on accepting temporal coincidence as persuasive grounds for what is really an inference; e.g. that smoke and fire are related simply because they appear together. How we conceive and delimit this temporal coincidence is an open question. Whether it requires actual immediacy or allows for a considerable delay is unclear from Sextus's text, though I doubt that Sextus would be very generous in allowing complicated inferences where direct correlation is debatable: for example, supposing that habitual Skeptical practice, and emphatically not a change in one's diet or the season, is what is primarily responsible for a general lightening of one's mood over a span of months.
} 
mitigated via the Skeptical method, but regarding which the Skeptic can never be confident whether her method is or will ever be effective, tends to expand even beyond the bounds of what we normally would be inclined to consider within the realm of belief. This ultimately leads the Skeptic to a general sense of the indeterminacy of the scope of the method and what is or is not possible by it.

\section{iii. The Uncertainty of the Sign and the Indetermination of the Method}

Consider the impressions of tarache as they assault the Skeptic. Some seem to follow from a clear and apparent cause, like physical discomfort or contemplation of an anomaly. These the Skeptic treats reflexively, either through suspension of judgement or practical action (drinking water, evading a threat). Immediate relief from these kinds of tarache is a determinate end of ordinary practice or Skeptical practice: because relief immediately and reliably follows upon the activity, the Skeptic need not indulge a belief about anything unclear by nature in order to want to act in these ways. These ends are absolutely necessary to prompt any action on the part of the Skeptic insofar as she does not maintain dogmatic beliefs; unless the connection between the action and its end is immediately and absolutely clear to her and does not rely upon beliefs, to act merely on the basis of a conjectural connection between action and end is inescapably dogmatic. Only a determinate end is able to justify Skeptical practice in light of Massie's objection to the indeterminate sense of ataraxia, and the immediate relief following after suspension of judgement in cases where the connection between tarache and a belief is apparent, namely as an anomaly, supplies just that determinate end which motivates Skeptical practice over other kinds of philosophical activity.

But other impressions do not have an apparent explanation, and the Skeptic knows that any attempt to theorize one will only generate more anomalies and more tarache. So instead she is resigned to fix only those problems the fixing of which does not cause even more problems. In addition to epoche in matters of belief, Sextus prescribes moderation in cases where our assent is forced (Sextus PH I 25). I would propose that in the case of inexplicable anxiety and frustration just as much as in the case of hunger and thirst, the Skeptic must content herself with using equipollence to mitigate those harmful beliefs that attach themselves to the offending impression, as when she is "afflicted by two sets of circumstances: by the feelings themselves, and no less by believing that these circumstances are bad by nature" (Sextus PH I 30). This is not necessarily because she is 'forced to assent' to anxiety in the same way that she is 'forced to assent' to thirst, but because she cannot identify the causes of that anxiety in her belief system and therefore has no place to begin to apply her Skeptical techniques (Sextus PHI 13). ${ }^{10}$ But even when the impression

\footnotetext{
10 See Vogt (2010) for a lengthy discussion of "forced assent" and the ways assent and approval of impressions are treated in the secondary literature. I have restricted my use of the term to the sense conveyed in $\mathrm{PH}$
} 
of anxiety is itself unclear, the belief that, say, anxiety is bad by nature is one that, when it presents itself clearly as a 'rider' augmenting the anxiety, can be subjected to suspension of judgement. Take the experience of being anxious about being anxious, or being angry with oneself for being angry; these secondary emotions may rest on beliefs about what sort of emotions are appropriate, beliefs that condition anxiety and anger in a more straightforward way and that therefore can be immediately identified and treated as problematic.

The experience of compound frustrations like this highlights the fundamental uncertainty of the Skeptic's situation, an uncertainty that Sextus does not explicitly account for. When she feels tarache, the Skeptic cannot necessarily tell if it is simple or composite in nature. When she is sad, or angry, or even hungry, how can she tell whether what she is feeling is biological in nature and best dealt with through food or chemicals, or whether it is related to beliefs she holds, or some mixture of both kinds of factors and still others? Though Sextus admits that the Skeptic is guided "by the necessitation of feelings" to do practical things like eat and drink, and that those "feelings forced upon" the Skeptic are not beliefs and are not subject to suspension, this does not mean that the feelings are totally reducible to biological factors or are unrelated to beliefs. (Sextus PH I 13, I 24). She feels tarache; possibly she feels it as a mess of affects, hunger and sadness and self-loathing all at once; she eats a snack; some of the tarache subsides, but while she can infer from this that sometimes eating a snack 'works', she cannot infer that her hunger is not also saddled with connections to emotionally-charged beliefs. All that is clear is that some relief followed the activity.

This is an important point, because it is tempting to theorize the categorical limitations of Skeptical practice based on a taxonomy of the conjectural sources of tarache. Perhaps even Sextus is guilty of this; whether or not his passages about hunger, thirst, and danger can be read in this way, it does not make it any less dogmatic. The Skeptic finds that in some situations food and drink alleviate some tarache, she finds that in other situations suspension of judgement alleviates some tarache, and she finds in still other situations that nothing she does makes her feel any better - but even if she finds the immediate benefits of Skeptical practice to be limited in scope, the potential benefits of Skeptical practice remain indeterminate precisely because that practice demands that she suspend judgement about the full unclear extent of its own efficacy. While she cannot believe that Skepticism will resolve all of her tarache, that it will ever miraculously bring her complete ataraxia, she also cannot disbelieve it; reprieve from any and all unclear afflictions might follow "as a shadow follows a body", and it is unclear whether any affliction with a clear and ready cause does not also have unclear origins or 'riders' (Sextus PH I 29). Nothing

I 25, and I mean to stress here that beliefs unclearly associated with tarache cannot be subjected to Skeptical equipollence because of the problem with making inferences, whereas the experiences of thirst and hunger are generally supposed to include tarache emanating from entirely outside the realm of belief. However, as I will note later in this paper, the Skeptic should consider that those urges which appear to force our assent may also be obscurely entangled with and augmented by our own beliefs, and she cannot even rule out the possibility that seemingly 'natural' urges can be entirely neutralized through suspension of judgement - a remote possibility to be sure, but not one that the Skeptic can once and for all foreclose. 
in the Skeptic's repertoire of arguments can guarantee relief from what is unclear, and attempting to divine the path will only lead to more tarache. Yet her incremental victories over tarache awaken the possibility, to which she cannot dogmatically assent but which she may at least entertain, that she is infinitely approaching this particular kind of atarax$i a$ like a curve converging on its asymptotic limit. This possibility is founded on nothing more (or less) than the radical indetermination of the extent to which beliefs are implicated in our tarache, an indetermination that reveals itself through a process of progressive un-determination of the apparently simple and solidly determined connections of ends and the means appropriate to achieving them. As the pervasiveness of this indetermination begins to dawn on the Skeptic who tirelessly challenges the inferential beliefs that undergird her determinations of the boundaries that circumscribe Skeptical inquiry, I would argue that the entire means-ends instrumentality of the therapeutic account of Skepticism begins to lose cohesion. The Skeptic, who initially adopted her practice to deal with specific problems, realizes that she can no longer specify which problems are subject to suspension of judgement or to what end she inquires. When all tarache must be treated as potentially compound and therefore indeterminate, the logic of determinate and indeterminate ends gives way to a functional and temporal endlessness.

\section{Conclusion: The Endlessness of the Skeptical Path}

In Book I of the Outlines Sextus famously compares his Skeptical arguments or "phrases" to "purgative drugs" that are "cancelled along with what they are applied to" and "drive themselves out [of the body] along with the humours [they drain]" (Sextus PH I 206). This, along with the previously quoted coda wherein Sextus compares his arguments to remedies devised for diverse dogmatic afflictions, might lead one to believe that Skeptical philosophy is nothing more than a spot-treatment for occasional concerns, and that the only difference between a Skeptic and her patient is that the Skeptic is "philanthropic" enough to share her insights with others (Sextus PH III 280). The practice would, according to this line of reasoning, leave no trace, no lasting mark on the frequent user; other than when one happens to be feeling "philanthropic", one is only a Skeptic when and for as long as one needs to be.

The foregoing discussion of the indeterminate ends and widening scope of Skepticism, however, makes it seem unlikely that it can be so modest or so dispensable as this. The patient who scrupulously follows her regimen of reflexive doubt, counter-argumentation, and suspension of judgement prescribed by Sextus for all beliefs "unclear by nature" will soon find that she can no longer assert when she does or she does not need her medication. On the one hand, she has no cause to suspend her judgement regarding beliefs when she does not perceive an anomaly. Ironically, when she is not actively juxtaposing arguments in a Skeptical fashion, and even when she is inclined to hold onto a belief because she perceives no anomaly or feels no tarache, her choice not to employ the Skeptical method conforms to the guidelines established by Sextus. His method subsumes her own 
inclinations by affirming her inclinations as the only reliable alternative to dogma. To say that she is only inclined to dabble in Skeptical arguments when she feels the need, and conversely that she, like a true disciple of Sextus, lets appearances dictate when to practice epoche, amounts to the same thing. The lay-Skeptic, therefore, is already involved in reflexively analyzing and determining the possible applications of epoche to diverse instances of tarache.

On the other hand, the treatment also recommends for prophylactic purposes that she avoid all dogmas, including the dogmas that suspension of judgement will only be effective against tarache produced by beliefs, that tarache produced by beliefs will always immediately appear as such, and that in cases where she has mitigated tarache by means other than suspension of judgement (such as by eating or drinking, or taking actual medication), the source of the tarache must have been wholly extra-dogmatic. The Skeptical method lends itself to problematizing the question of when it is appropriate to apply the Skeptical method. The appearance of tarache as tarache is never in doubt, nor is the appearance of the occasional direct utility of both Skeptical inquiry and other means to relieve tarache, so the expanding domain of indetermination via the progressive un-determination of inferred connections between effects and causes, and thus between ends and means, does not necessarily lead to apraxia, the inability to act or to inquire. What it instead brings about is the underdetermination of ataraxia, that notional goal of self-emancipation from tarache that can only be concretely determined by a dogmatic theory of the causes, varieties, and dynamics of tarache. The Skeptical therapy is originally adopted to achieve certain clear and definite ends like the relieving of tarache immediately following upon perception of an anomaly, and conceived with an eye towards the indeterminate goal of total ataraxia as far as that is possible; but while it may succeed in both directly and indirectly relieving tarache, it also undermines the very criteria that determine its own success and, crucially, whether it can ever be said to have achieved its goal, or whether it can ever be said to have run up against a hard limit. Perhaps Barnes is not far off in his description of the beginning of Skepticism, its initial uptake, as a fairly innocuous and 'Urbane' habit for managing one's troubling penchant for wondering and worrying over some philosophical quandaries. But what he fails to realize is that to remain an Urbane Skeptic in the sense he describes is to assent to the belief, whether or not one does so consciously, that there are kinds of tarache beyond the scope of equipollence, and that the best the Skeptic can hope for is relief from this one kind of ailment among the many that afflict her in life.

Before I conclude, I would like to point out that throughout this paper I have been concerned with the practical value rather than the historical significance of the Skeptical program advocated by Sextus. I have drawn attention to brief, provocative passages from Sextus's Outlines which suggest alternative relationships between belief and tarache to the one which receives by far the most attention from Sextus, that of the "perceived anomaly" between arguments or appearances, merely in order to show that the Skeptical method demands that we question our own assumptions about the way Skepticism works, and the various assumptions passed on to us by those who came before us, including 
all the historical founders of the various schools of Skepticism from Pyrrho to Sextus. David Sedley (1983) wanted to understand the specific motivations (stated or implied) of the various Greek Skepticisms, of their founders and followers. I instead wanted to understand the motivations of a hypothetical Skeptic, Greek or no, who takes to heart everything Sextus has written on, but who is willing to go beyond his specific prescriptions and entertain possibilities that had never occurred to him. I wanted to understand how her motivations might sustain her Skeptical practice, and how her practice might transform her understanding of her own aims. In this respect I have been influenced by Michael William's reappraisal of Skepticism as a compelling and enduringly viable lifestyle, one rooted in a "simple rule for thinking" and not in any theory of how that rule is to be followed (Williams 1988).

We have previously considered Massie's question whether and in what sense the Skeptic can justifiably be called a Skeptikos, a perpetual searcher, if like other philosophers she is seeking after a definite end that would also put an end to her search. He proposes one solution, that "the inquisitive activity of the desiring intellect is itself valuable" for the Skeptic (Massie 2013: 230). For him, it swiftly knocks out two birds with one stone - an intrinsic value in the activity of inquiry would supply both a determinate end to initiate the search, and a guarantee of an endless supply of new ends so that the Skeptic will continue inquiring until the end of time, long after the philosopher has found his Truth and stopped searching. But we have already shown that relief from tarache immediately reinforces the Skeptic's confidence in her practice whenever she resolves a troubling conundrum through equipollence. And perhaps instead of positing an infinite chain of ends, we can settle for the indeterminate end Sextus provides, ataraxia, with one caveat. While ataraxia, just like the philosopher's Truth or Good, is the kind of end that, if attained, would put an end to inquiry; and while the possibility that neither the philosopher nor the Skeptic will find what she is looking for in her lifetime does not by itself obviate the fact that her activity posits a fixed (though indeterminate) end and thereby undermines the claim to be potentially unending; the critical difference between their uncertain searches is that presumably the philosopher will know his goal when he has attained it, while the Skeptic will always be obliged to suspend judgement as to whether she has reached the very limit of equipollence, the point where all tarache that can possibly be vanquished through suspension of beliefs alone has been vanquished and all remaining tarache is of a different nature and therefore inextinguishable. Hypothetically if she were to reach a state of total ataraxia and remain that way, she would then cease searching, but whereas the philosopher posits the actual existence of a truth that would put an end to his own search, the Skeptic is neither confident that she can completely abolish all tarache, including the kind that is generally taken to be natural and unavoidable (hunger and fear, for instance), nor convinced that if she were to come up against the limits of belief and reality, she would recognize that limit. So while she entertains the possibility that her search could come to an end - to not entertain that possibility would be dogmatic - she also recognizes that outside of that ultimate scenario, she does not have a vantage point of certain knowledge from which she can evaluate 
her journey and decide when to stop. Inquiry may bear valuable fruit in the form of relief from many kinds of tarache, but in itself it is invaluable - perhaps ultimately of infinite value (yielding unconditional ataraxia), perhaps ultimately worthless (condemning her to perpetual uncertainty), but in any case strictly in-valuable, unable to be reliably evaluated or valuated. 


\section{BIBLIOGRAPHY}

BARnes, J., 1997, “The Beliefs of a Pyrrhonist,” in: M. Burnyeat, M. Frede (eds.), The Original Sceptics: A Controversy, Indianapolis, pp. 58-91.

BERrY, J.N., 2011, Nietzsche and the Ancient Skeptical Tradition, New York.

Burnyeat, M., 1997, “The Sceptic in His Place and Time,” M. Burnyeat, M. Frede (eds.), The Original Sceptics: A Controversy, Indianapolis, pp. 92-126.

Everson, S., 1991, “The Objective Appearance of Pyrrhonism,” in: S. Everson (ed.), Companions to Ancient Thought 2. Psychology, Cambridge, pp. 121-147.

Long, A.A., Sedley, D.N., 1987, The Hellenistic Philosophers, Cambridge.

Massie, P., 2013, "Philosophy and Ataraxia in Sextus Empiricus," Peitho. Examina Antiqua 1.4, pp. 211-234.

SEDLEY, D., 1983, “The Motivation of Greek Skepticism,” in: M. Burnyeat (ed.), The Skeptical Tradition, Berkeley, pp. 9-29.

SeXtus, 1994, Outlines of Scepticism, transl. J. Annas, J. Barnes, Cambridge.

Vogt, K.M., 2010, “Skepticism and Action,” in: R. Bett (ed.), The Cambridge Companion to Ancient Scepticism, Cambridge, pp. 165-180.

Williams, M., 1988, “Scepticism Without Theory,” The Review of Metaphysics 41.3, pp. 547-588

BRYA N M A DDOX

/Oxford $\mathrm{OH} /$

\section{On the Motivations of a Skeptic, and Her Practice}

The aim of Pyrrhonism is deceptively simple: to achieve a state of ataraxia, of tranquility and relief from perturbation. But what is the extent of the ataraxia envisioned? Must the Skeptic admit a hard distinction between disturbances apparently related to belief and therefore subject to suspension of judgement, and extra-doxastic disturbances (e.g. everyday anxiety and frustration, or even hunger and fear) that are beyond the scope of the Skeptical method? In this paper I examine passages from Sextus's Outlines of Pyrrhonism that indicate that such a distinction may not stand up to Skeptical scrutiny and that the Skeptical method does not only apply to "philosophical" speculative dogma or to "intellectual" perturbation, contra Barnes's claim that the person who perceives the fewest anomalies may make "the perfect Pyrrhonist". But I also, following Massie's critique of unwarranted causal inferences regarding the relation between equipollence and ataraxia, distinguish cases where tarache (disturbance) presents itself as anomalous and thus lends itself to inquiry from cases where it presents itself with an apparent cause and does not provoke inquiry. Thus, though an apparently extra-doxastic disturbance may actually be rooted in unconsciouslyheld dogma, the Skeptic cannot demarcate a special class of potentially doxastic disturbances without employing a dogmatic psychology of her 
own. She must instead suspend judgment regarding the entire scope of her method, entertaining the possibility that any disturbance could be relieved through the Skeptical method. In the process, ataraxia is divested of definite parameters and the Skeptical method becomes effectively endless. 